\title{
The validity of current guidelines regarding surgical management of patients with gastric neuroendocrine neoplasms type 1: a report of a series of seven patients
}

\author{
Georgios Boutzios, ${ }^{2}$ John Griniatsos, ${ }^{1}$ Nikoletta Dimitriou, ${ }^{1}$ Athanassios Zilos, ${ }^{2}$ \\ Stavroula Antoniou, ${ }^{2}$ Evangelos Felekouras, ${ }^{1}$ Gregory Kaltsas ${ }^{2}$ \\ ${ }^{1} 1^{\text {st }}$ Department of Surgery, ${ }^{2}$ Endocrine Unit, Department of Pathophysiology, University of Athens, Medical School, \\ Laiko Hospital, Athens, Greece
}

\begin{abstract}
OBJECTIVE: Gastric neuroendocrine neoplasms Type 1 (GEN type 1) are mostly localized indolent tumors, with only a minority developing lymph node or distant metastasis. Although they are usually managed conservatively, large, invasive, recurrent and grade 2 lesions may require surgical treatment. The aim of this case series is to evaluate the validity of current guidelines regarding surgical management of patients with GEN type 1. CASES: Seven patients (5 female) with GEN type 1 underwent peri-gastric lymphadenectomy when at least one of the following criteria employed in previous guidelines was present: (i) multiple recurrent lesions, (ii) lesions with positive margins following endoscopic resection, (iii) lesions with malignant potential (deep gastric parietal wall invasion, lymph node enlargement, Ki67 proliferative index $>2 \%$ ), or (iv) presence of metastatic disease. Four patients met one and three two of the previously defined criteria; fifteen to thirty-six peri-gastric lymph nodes were resected. Following surgery there was no alteration in tumor staging status compared to pre-surgical staging. During a median follow-up of 34 months, all patients remain without any evidence of disease recurrence. CONCLUSION: Peri-gastric lymphadenectomy did not prove to be necessary for localized GEN type 1, neither for staging nor for therapeutical reasons. Further parameters need to be evaluated to identify the small subset of patients that will develop more aggressive disease.
\end{abstract}

Key words: Enterochromaffin-like cell hyperplasia, Gastric neuroendocrine neoplasms Type 1, Gastric resection

Address for correspondence:

Georgios Boutzios, Endocrine Unit, Department of

Pathophysiology, University of Athens, Medical School,

Tel.: +30 2107462513, Fax: +30 2107462664,

E-mail:gboutzios@gmail.com

Received 03-04-2013, Accepted 29-04-2013

\section{INTRODUCTION}

Gastric endocrine neoplasms (GENs) are among the most common gastroenteropancreatic (GEP) neuroendocrine tumors (NETs) that develop from the enterochromaffin-like (ECL) cells of the gastric 
corpus mucosa and are classified into three main types based on clinicopathological characteristics, behaviour and prognosis. ${ }^{1,2}$ GENs represent up to $23 \%$ of all digestive neuroendocrine neoplasms with a yearly age-adjusted incidence of around 0.2 per population of $100,000 .{ }^{3}$ GENs type 1 are the most common (70-80\%) gastric NETs associated with chronic atrophic gastritis, achlorhydria induced hypergastrinemia, with or without pernicious anemia. ${ }^{3}$ Along with GENs type 2 (5-6\%), that are related to a gastrin secreting neoplasm in the context of multiple endocrine neoplasia 1 (MEN-1) syndrome, they can be multiple and present an indolent course compared to GEN type 3, that are single lesions not associated with ECL-hyperplasia behaving in a malignant manner. GENs type 1 are almost exclusively 'benign' lesions with a small risk of deep gastric parietal wall invasion. ${ }^{4}$ These tumors exhibit a low rate (3-8\%) of lymph node invasion but nodal involvement is not directly related to GEN-specific death. ${ }^{1}$ However, $2-5 \%$ of patients may still develop distant metastases and $10 \%$ have already local or distal spread. ${ }^{5,6}$ Previous guidelines published by the European Neuroendocrine Tumor Society (ENETS) have advocated surgery in the presence of multiple and recurrent lesions, deep gastric parietal wall invasion and Ki67 index $>2 \%{ }^{7}$ However, it has recently been suggested that surgery should mainly be performed in the presence of involvement beyond submucosa, or positive margins after endoscopic mucosal resection (EMR). ${ }^{8}$ Surgery should also be performed in the presence of lymph nodal or distant disease spread, adverse histological findings and poorly differentiated neoplasms. ${ }^{8}$

Besides the findings of a study that neither size $\geq 10 \mathrm{~mm}$ nor the depth of tumor infiltration nor the multicentric nature of the disease (so-called 'high risk' patients) $)^{9}$ correlate with outcome, recent studies have shown that $29-56 \%$ of GEN type 1 are still treated surgically. ${ }^{1,9}$ However, neither the indications nor the type of gastric resection are clearly stated. This is particularly relevant as treatment with long-acting somatostatin analogues (SSAs) $)^{10,11}$ has been shown to reduce tumor size and serum gastrin level, ${ }^{12}$ although this form of treatment is not currently recommended by the ENETS. ${ }^{8}$ In order to identify patients at higher risk for a more aggressive course of the disease in this study, we report a series of seven patients with GEN type 1 who underwent a modified gastrectomy as they were considered 'high risk' patients on the basis of the previously implemented ENETS guidelines. ${ }^{7}$

\section{PATIENTS REPORT}

\section{A mini series of seven cases}

Between 2004 and 2010, seven patients who had been diagnosed with GEN type 1 and met at least one of the following criteria were enrolled in the study: (i) multiple recurrent lesions, (ii) lesions with positive margins following endoscopic resection, (iii) lesions with malignant potential (deep gastric parietal wall invasion, lymph node enlargement, Ki67 proliferative index $>2 \%$ ), or (iv) presence of local metastatic disease (Table 1). ${ }^{7}$ All subjects participating underwent a subtotal gastrectomy with dissection of the regional lymph nodes by the same surgeon. This surgical approach was chosen instead of an antrectomy as per previous and current guidelines, since the primary aim of the study was to evaluate the presence of locoregional spread in patients considered to be at higher risk. ${ }^{7,8}$ The study was approved by the Ethics Committee of the Medical University and all patients gave informed consent.

In all patients, the diagnosis of GEN type 1 was established via an upper gastrointestinal (GI) tract endoscopy and the histological examination of endoscopic polypectomy specimens; multiple biopsies were taken from suspicious lesions along with biopsies from normal looking mucosa. If a solitary polypoid lesion was found, endoscopic polypectomy was performed; if a sessile lesion was found, multiple biopsies were taken, while in the case of multiple lesions, polypectomies and/or biopsies of all suspicious lesions were performed.

Preoperatively, all patients had undergone appropriate laboratory (serum gastrin and chromogranin $\mathrm{A}(\mathrm{CgA})$ measurements) and imaging investigations for evaluation of disease spread and exclusion of the Zollinger-Ellison and MEN-1 syndromes. All patients underwent either computerized tomography (CT) and/ or Magnetic Resonance Imaging (MRI) of the abdomen, as well as scintigraphy with ${ }^{111}$ In-pentetreotide ${ }^{13}$ (Octreoscan) (Table 1). Endoscopic ultrasound (EUS) was performed in four patients (Table 1), showing peri-gastric lymph node enlargement in only two of them. The investigational algorithm was evolving during the period of the study as access to all imag- 
Table 1. Clinical, radiological and histopathological findings before and after treatment in the 7 patients included in the study

\begin{tabular}{|c|c|c|c|c|c|}
\hline $\begin{array}{l}\text { Sex } \\
\text { Age }\end{array}$ & Preoperative endoscopic findings & $\begin{array}{l}\text { Preoperarive } \\
\text { histology }\end{array}$ & $\begin{array}{l}\text { Preoperative } \\
\text { treatment }\end{array}$ & $\begin{array}{l}\text { Preoperative } \\
\text { imaging findings }\end{array}$ & Postoperative histology \\
\hline F/46 & $\begin{array}{l}\text { 1. Caulifower-like antral tumor } \\
(3,5 \mathrm{~cm}) \text {. Ulcerative antral tumor. }\end{array}$ & $\begin{array}{l}\text { Well differentiated } \\
\text { GEN }\end{array}$ & No & $\begin{array}{l}\text { MRI: Hepatic } \\
\text { metastases } \\
\text { Octreoscan: (-) }\end{array}$ & $\begin{array}{l}\text { NET: Primary tumor Ki67 } \\
2 \%, \text { metastasis Ki67 8\% }\end{array}$ \\
\hline F/41 & $\begin{array}{l}\text { 2. Multiple gastric polypoid } \\
\text { lesions. Persisting multicentric } \\
\text { or recurrent submucosal lesions } \\
\text { in the body of the stomach }\end{array}$ & $\begin{array}{l}\text { Persistent or } \\
\text { recurrent well } \\
\text { differentiated GEN }\end{array}$ & $\begin{array}{l}\text { SSA for } \\
\text { three years }\end{array}$ & $\begin{array}{l}\text { MRI: (-) } \\
\text { Octreoscan: (-) }\end{array}$ & $\begin{array}{l}\text { No evidence of } \\
\text { residual disease (cured } \\
\text { endoscopically before } \\
\text { surgery) }\end{array}$ \\
\hline $\mathrm{M} / 44$ & $\begin{array}{l}3 \text {. Solitary polypoid lesion in the } \\
\text { body of the stomach. Solitary } \\
7 \times 5 \times 5 \mathrm{~mm} \text { polypoid lesion in } \\
\text { the body of the stomach }\end{array}$ & $\begin{array}{l}\text { Well differentiated } \\
\text { GEN with } \\
\text { submucosa lymphatic } \\
\text { invasion } \mathrm{Ki} 67>2 \%\end{array}$ & No & $\begin{array}{l}\text { MRI: Lymph node } \\
\text { enlargement along } \\
\text { the left gastric } \\
\text { artery } \\
\text { Octreoscan: (-) }\end{array}$ & $\begin{array}{l}\text { No evidence of } \\
\text { residual disease (cured } \\
\text { endoscopically before } \\
\text { surgery) }\end{array}$ \\
\hline$F / 36$ & $\begin{array}{l}\text { 4. Multiple polypoid lesions } \\
\text { in the body and antrum of the } \\
\text { stomach }\end{array}$ & $\begin{array}{l}\text { Well differentiated } \\
\text { GEN infiltrating } \\
\text { the submucosa \& } \\
\text { muscular propria } \\
\text { Ki67 1.1\% }\end{array}$ & $\begin{array}{l}\text { SSA for five } \\
\text { years }\end{array}$ & $\begin{array}{l}\text { MRI: Lymph node } \\
\text { enlargement along } \\
\text { the celiac axis } \\
\text { Octreoscan: (-) }\end{array}$ & $\begin{array}{l}\text { No evidence of } \\
\text { residual disease (cured } \\
\text { endoscopically before } \\
\text { surgery) }\end{array}$ \\
\hline $\mathrm{F} / 32$ & $\begin{array}{l}\text { 5. Solitary polypoid lesion } \\
\text { in the body of the stomach. } \\
\text { Solitary } 1.2 \mathrm{~cm} \text { polypoid lesion in } \\
\text { the body of the stomach }\end{array}$ & $\begin{array}{l}\text { GEN infiltrating } \\
\text { the submucosa with } \\
\text { positive resection } \\
\text { margins Ki67 5-10\% } \\
\text { with nuclear atypia }\end{array}$ & No & $\begin{array}{l}\text { MRI: (-) } \\
\text { Octreoscan: small } \\
\text { uptake near to the } \\
\text { left kidney (finding } \\
\text { not confirmed } \\
\text { postoperatively) }\end{array}$ & $\begin{array}{l}\text { No evidence of } \\
\text { residual disease (cured } \\
\text { endoscopically before } \\
\text { surgery) }\end{array}$ \\
\hline $\mathbf{F} / \mathbf{5 2}$ & $\begin{array}{l}\text { 6. Multiple polypoid lesions } \\
\text { in the antrum and body of the } \\
\text { stomach }\end{array}$ & $\begin{array}{l}\text { Well differentiated } \\
\text { GEN with Ki67 5\% }\end{array}$ & No & $\begin{array}{l}\text { MRI: (-) } \\
\text { Octreoscan: (-) }\end{array}$ & $\begin{array}{l}\text { Well differentiated } \\
\text { neuroendocrine tumor } \\
\text { extending up to the } \\
\text { submucosal muscular is } \\
\text { propria (sm1) }\end{array}$ \\
\hline $\mathrm{M} / 66$ & $\begin{array}{l}\text { 7. Multiple gastric and duodenal } \\
\text { lesions. Persistent polypoid } \\
\text { lesions in the body and antrum } \\
\text { of the stomach as well as in the } \\
1^{\text {st }} \text { portion of duodenum }\end{array}$ & $\begin{array}{l}\text { Well differentiated } \\
\text { GEN not involving } \\
\text { the submucosa, } \\
\text { atrophic gastritis }\end{array}$ & No & $\begin{array}{l}\text { MRI: (-) } \\
\text { Octreoscan: (-) }\end{array}$ & $\begin{array}{l}\text { Gastric neuroendocrine } \\
\text { tumor with low malignant } \\
\text { potential }\end{array}$ \\
\hline
\end{tabular}

GEN: Gastric endocrine neoplasm, SSA: Somatostatin analogues, MRI: Magnetic Resonance Imaging

ing studies, mainly EUS, was not readily available. Administration of long-acting SSA was chosen as first therapeutic option in two patients for three and five years, respectively, leading however to recurrence of the disease in both of them at discontinuation.

\section{Surgical technique}

The dissection of the regional lymph nodes was based on the Japanese Classification of Gastric Carcinoma. ${ }^{14}$ Thus, for the modified (D2) lymphadenectomy, the appropriate (depending on the location of the primary tumor) nos. 1-6 lymph node stations, as well as nos. 7, 8a, 9, 11p, 11d and 12a lymph node stations were routinely dissected (Figure 1). Level II lymph node stations were recognizable as they were sent separately to the Pathology Department with special indices demonstrating their exact location. Dissection of no. 10 lymph node station, splenectomy or distal pancreatectomy was not performed in any of the patients.

\section{Follow-up}

Patients following postsurgical resection underwent abdominal MRI, Octreoscan and CgA levels 


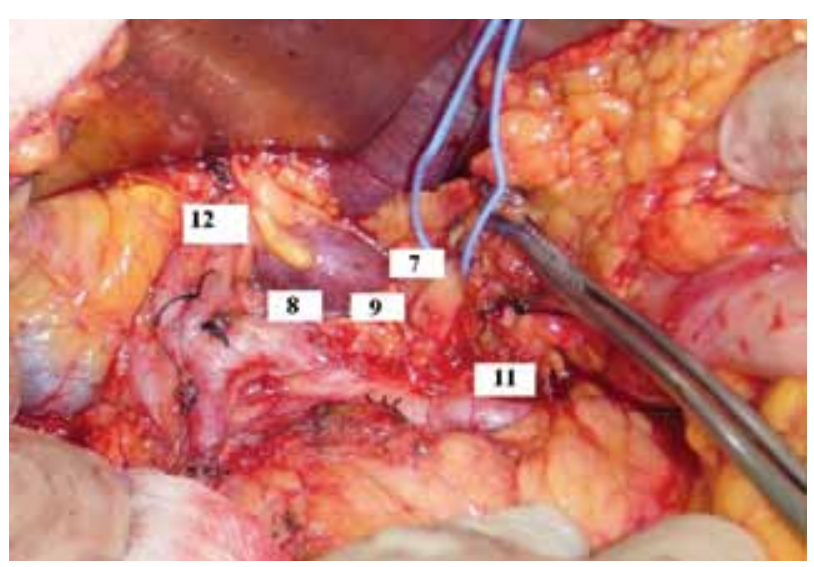

Figure 1. Subtotal gastrectomy with modified D2 lymphadenectomy. The distal resection margin has already been cut just distal to the pylorus and the whole specimen has been moved upwards (under the fingers of the assistant on the right). Nos. 1-6 lymph node stations (peri-gastric lymph nodes) alongside the lesser and greater curvature are not shown, since they are attached to specimen. After entrance into the lesser sac and identification of the main vessels, meticulous dissection along them leads to the dissection of no. 12 (hepatoduodenal ligament along hepatic artery and bile duct), no. 8 (anterosuperior group along the common hepatic artery), no. 9 (celiac artery), no. 7 (left gastric artery) and no. 11 (proximal and distal splenic artery) lymph node stations.

at 6 months. If the Octreoscan was negative, further follow-up was based on $\mathrm{CgA}$ measurement and MRI imaging at 6 and 12 months, respectively, for at least 3 years, according to the ENETS guidelines, to ensure biochemical and morphological eradication of disease. ${ }^{8}$

\section{Analysis of cases}

Seven patients, with median age of 44 years (range 32-66 years), were enrolled in the study. A history of Hashimoto's thyroiditis was present in three and pernicious anemia in four patients. According to the inclusion criteria used, four patients fulfilled one and three two of the criteria for surgical resection (Table 1).

Preoperative endoscopy disclosed an ulcerative tumor in one, solitary polypoid lesions in two and multiple mucosal or submucosal lesions in three patients, while hypergastrinemia, atrophic gastritis, enteric metaplasia and significant hyperplasia of the ECL-cells were histologically confirmed in all. All patients had previously undergone endoscopic pol- ypectomy. Preoperative EUS scan was suggestive of peri-gastric lymph node involvement in two patients.

Five patients underwent a subtotal gastrectomy, one a near total gastrectomy, while the patient with known hepatic metastases underwent a simultaneous subtotal gastrectomy and metastasectomy. A median of 21 (range 15-36) perigastric lymph nodes were histologically retrieved from each patient. In the gastrectomy specimens visible tumor was found only in the patient with the preoperative diagnosis of an ulcerative lesion. None of the studied patients was found to have lymph node involvement. None of the patients had any peri- or postoperative complications. Preoperative plasma gastrin levels ranged between 252 to $1188 \mathrm{pg} / \mathrm{mL}$ (median $835 \mathrm{pg} / \mathrm{mL}$-normal value $<108 \mathrm{pg} / \mathrm{mL}$ ), while postoperative levels ranged from 2 to $38 \mathrm{pg} / \mathrm{mL}$ (median $20.5 \mathrm{pg} / \mathrm{mL}$ ). Preoperative plasma CgA levels ranged between 102 to $600 \mathrm{ng} / \mathrm{ml}$ (median 285ng/ml - normal value $19.4-98.1 \mathrm{ng} / \mathrm{ml}$ ), while postoperative levels ranged from 21 to $39.8 \mathrm{ng} /$ $\mathrm{ml}$ (median 33.8ng/ml).

During a median follow-up period of 34 months (range 2-84 months), all patients remain alive without any evidence of disease recurrence. Gastrin and $\mathrm{CgA}$ plasma levels remained within the normal range in all patients. Imaging findings did not show any evidence of recurrence during the follow-up period.

\section{DISCUSSION}

GENs type 1 are mostly multiple indolent tumors, less than $2 \mathrm{~cm}$ in size, that in their great majority are confined to the gastric mucosa. ${ }^{3}$ However, a subset, for which there are no known predictive factors, may develop more advanced disease, with lymph node and/ or hepatic metastases..$^{15}$ The findings of the present small series suggest that a more aggressive surgical approach failed to identify locoregional disease in patients considered to be at risk for localized or distant disease spread on the basis of specific inclusion criteria that had been implemented in previous ENETS guidelines. ${ }^{7}$ These findings are in agreement with the latest ENETS guidelines that favor a more conservative approach. ${ }^{8}$ Therefore, such a surgical approach is not advocated and further criteria need to be employed to identify patients at higher risk for more aggressive disease. 
GENs type 1 have an overall good prognosis, with a 5-year survival rate of $96 \%$, which is not different to an age-matched normal population. ${ }^{11}$ Recently, ENETS has published specific guidelines regarding the management of these tumors. ${ }^{8}$ It is recommended to remove all GENs type 1 (also known as ECLomas) whenever possible; however, there are no data suggesting that the evolution of the disease may be less favorable if tumors $<1 \mathrm{~cm}$ are left in place. In the case of tumors greater than $1 \mathrm{~cm}$, EUS should be performed to assess wall and lymph nodal invasion before polypectomy by snare or endoscopic mucosal resection. ${ }^{8}$ However, there are no long-term data available regarding the efficacy of this approach and/ or recurrence of the disease due to persisting ECL hyperplastic foci in the remaining part of the stomach. Gastric surgery is performed as per new guidelines in the presence of lymph nodal or distant disease spread and poorly differentiated neoplasms. ${ }^{8}$

We opted of a modified subtotal D2 lymphadenectomy as a standard surgical procedure, mainly for staging purposes, particularly as in some cases there was radiological evidence of lymph node enlargement. This was considered necessary as several recent studies have shown that tumor spread based on the TNM classification system correlates well with outcome and prognosis in patients with GEP-NETs, whereas ENETS has also introduced a TNM classification system for GENs type $1 .{ }^{8}$ We hypothesized that identifying patients at risk for developing at least localized disease could potentially identify patients at risk for developing distant metastases. Although the procedure was well tolerated and no side-effects were recorded, none of the selected patients was found to have lymph node involvement. The findings in this small series are in concordance with the overall excellent prognosis of patients with GEN type 1 and argue against the use of a more aggressive approach even in the presence of potentially adverse risk factors.

In conclusion, these data provide evidence that the recently introduced ENETS guidelines that are in favor of a more conservative approach in previously considered 'high risk' patients are clinically meaningful. Further parameters need to be evaluated to identify the small subset of patients that will develop more aggressive disease.

\section{CONFLICT OF INTEREST}

The authors declare that they have no competing interests.

\section{REFERENCES}

1. Gladdy RA, Strong VE, Coit D, et al, 2009 Defining surgical indications for type I gastric carcinoid tumor. Ann Surg Oncol 16: 3154-3160.

2. Modlin IM, Lye KD, Kidd M, 2003 A 5-decade analysis of 13,715 carcinoid tumors. Cancer 97: 934-959.

3. Niederle MB, Hackl M, Kaserer K, Niederle B, 2010 Gastroenteropancreatic neuroendocrine tumours: the current incidence and staging based on the WHO and European Neuroendocrine Tumour Society classification: an analysis based on prospectively collected parameters. Endocrine-related cancer 17: 909-918.

4. Rindi G, Azzoni C, La Rosa S, et al, 1999 ECL cell tumor and poorly differentiated endocrine carcinoma of the stomach: prognostic evaluation by pathological analysis. Gastroenterology 116: 532-542.

5. Modlin IM, Lye KD, Kidd M, 2003 Carcinoid tumors of the stomach. Surg Oncol 12: 153-172.

6. Rappel S, Altendorf-Hofmann A, Stolte M, 1995 Prognosis of gastric carcinoid tumours. Digestion 56: 455-462.

7. Ruszniewski P, Delle Fave G, Cadiot G, et al, 2006 Well-Differentiated Gastric Tumors/ Carcinomas. Neuroendocrinology 84: 158-164.

8. Delle Fave G, Kwekkeboom DJ, Van Cutsem E, et al, 2012 ENETS Consensus Guidelines for the management of patients with gastroduodenal neoplasms. Neuroendocrinology 95 74-87.

9. Borch K, Ahren B, Ahlman H, 2005 Gastric carcinoids: biologic behavior and prognosis after differentiated treatment in relation to type. Ann Surg 242: 64-73.

10. Manfredi S, Pagenault M, de Lajarte-Thirouard AS, Bretagne JF, 2007 Type 1 and 2 gastric carcinoid tumors: long-term follow-up of the efficacy of treatment with a slow-release somatostatin analogue. Eur J Gastroenterol Hepatol 19: 1021-1025.

11. Grozinsky-Glasberg S, Kaltsas G, Gur C, et al, 2008 Long-acting somatostatin analogues are an effective treatment for type 1 gastric carcinoid tumours. Eur $\mathbf{J}$ Endocrinol 159: 475-482.

12. Campana D, Nori F, Pezzilli R, et al, 2008 Gastric endocrine tumors type I: treatment with long-acting somatostatin analogs. Endocr Relat Cancer 15: 337-342.

13. Thomas D, Tsolakis AV, Grozinsky-Glasberg S, et al, 2012 Long-term follow-up of a large series of patients with type 1 gastric carcinoid tumors. Data from a multicenter study. Eur J Endocrinol. 168: 185-193.

14. Japanese Gastric Cancer Association, Japanese Classification of Gastric Carcinoma, 2nd English Edition 1998. Gastric Cancer 1: 10-24.

15. Modlin IM, Lye KD, Kidd M, 2004 A 50-year analysis of 562 gastric carcinoids: small tumor or larger problem? Am J Gastroenterol 99: 23-32. 